\title{
ยก
}

\section{Materiais Didáticos para Educação a Distância: Observando}

\section{Layouts}

\author{
Dorcas Janice Weber ${ }^{1}$, Lia Raquel Oliveira²
}

\begin{abstract}
1 Doutoranda da Universidade do Minho e Professora do Departamento de Música, Instituto de Artes, Universidade Federal do Rio Grande do Sul, Rua Senhor dos Passos, 248 - Centro - Porto Alegre - RS - Brasil. dorcasjweber@gmail.com
\end{abstract}

2 Professora Doutora do Departamento de Ciências da Educação, Universidade do Minho, Largo do Paço Braga - Portugal. lia@ie.uminho.pt

\section{Resumo}

A inserção da educação a distância nos processos educativos formais apontou possibilidades de formação em nível superior para aqueles que estão distantes dos centros de formação e, para além disso, desvelou objetos de investigação. Um exemplo disso são os materiais didáticos, tão necessários para a efetivação da aprendizagem na modalidade a distância. A gama de materiais é grande e, por isso, é interessante conhecer o modo como eles vêm sendo desenvolvidos e utilizados por aquelas instituições que ofertam cursos nessa modalidade. É sabido que há necessidades distintas entre os alunos da educação a distância e os de cursos presenciais, que precisam estar contempladas nos materiais didáticos. Mas de fato estão? Considerando a organização do espaço de estudo como importante no processo pedagógico, como os espaços dos materiais didáticos vêm sendo organizados? Que elementos têm sido utilizados para o desenvolvimento de layouts para materiais didáticos utilizados em cursos a distância? Tais questões são tema deste escrito, que busca, a partir de um estudo de caso, observar materiais didáticos produzidos para cursos brasileiros a distância. Um olhar transversal sobre tais materiais aponta semelhanças com os produtos elaborados para a educação presencial, tão conhecida por muitos.

Palavras-chave: Educação a distância; Materiais didáticos; Layout. 


\title{
Didactic Materials for Distance Education: Observing Layouts
}

\begin{abstract}
The inclusion of distance education in formal educational processes pointed training opportunities in higher education for those who are distant from training centers and, in addition, unveiled research objects. An example of this are the didactic materials, as necessary for effective learning in the distance. The range of materials is large and therefore it is interesting to know how these are being developed and used by those institutions that offer courses in this modality. It is known that there are different needs among students of distance education and presence courses that need to be addressed in didactic materials. But actually are? Considering the organization of study space as important in the educational process, as the spaces of didactic materials have been organized? What elements have been used to development layouts for the materials used in distance education courses? This questions are theme of this this written that will, with a case study, observe didactic materials produced to Brazilian distance courses. That observation shown us that analyzed materials have similarities with didactic products for face to face education.
\end{abstract}

Keywords: Distance education; Didactic materials; Layout. 


\section{Introdução}

Cursos brasileiros de graduação ofertados na modalidade a distância têm se tornado um atrativo a mais no que diz respeito à realização de um curso em nível superior. O que, há poucos anos, era visto com olhos de desconfiança passou a figurar como uma opção a ser considerada. O aumento no número de pessoas interessadas em estudar nessa modalidade faz elevar a sua oferta e, por consequência, despontam campos de trabalho e objetos de investigação a partir das especificidades desses cursos. Um exemplo disso são os materiais didáticos, que, tempos atrás, restritos ao livro impresso no contexto do ensino superior, têm despontado como um novo campo de atuação profissional e pesquisa acadêmica.

Materiais didáticos são artefatos culturais presentes na memória e no cotidiano de pessoas em diferentes culturas. O avanço tecnológico ampliou consideravelmente as possibilidades de tipologias de materiais, tornando o livro impresso, tão conhecido e criticado, apenas mais um dentre aqueles que compõem a lista de opções. Objetos de aprendizagem modulares que podem ser específicos e, se agrupados, acabam por se tornar complexos, como ressaltam Grando, Konrath e Tarouco (2003), são um exemplo de produto pedagógico que despontou com a educação a distância (EAD) mediada pelas novas tecnologias. Com isso, ampliou-se também o entendimento sobre o que é considerado material didático. Weber e Oliveira (2013) também atentam para o fato de que o avanço das tecnologias da informação e comunicação (TIC) possibilitou outro modo de desenvolver a EAD, o qual necessita de materiais distintos, para além do impresso. Ainda, autores como Moran (2002), Illera (2010) e Belisário (2006) têm apontado a necessidade de estruturar materiais didáticos específicos para a EAD, tendo em conta as funções que lhes são atribuídas nesse contexto. Peters (2009) alerta que os processos comunicativos na EAD ocorrem de modo não natural, uma vez que são mediados pelas tecnologias; assim, diferentemente das ações que ocorrem na sala de aula tradicional, onde o professor realiza a mediação entre material didático e alunos, na EAD os materiais realizam a mediação entre o discurso do professor e os alunos.

Diante disso, é preciso que todos os elementos que constituem um material didático sejam atentamente considerados, a fim de promover a aprendizagem. Os materiais devem ser compreendidos não apenas nos seus conteúdos verbais, mas também nos elementos que o configuram, como alerta Illera (2010), ao dizer que as multilinguagens estão, cada vez mais, a fazer parte dos produtos pedagógicos. Vale 
atentar, também, para o fato de que os materiais didáticos, além de seu conteúdo verbal e ilustrativo, apresentam uma série de elementos visuais utilizados como ferramentas de design gráfico, que constituem seu layout, podendo promover motivação e organização, aliados ao processo de aprendizagem. As discussões que abordam esses elementos de design e organização visual em publicações são, em geral, realizadas por designers e, muitas vezes, no contexto publicitário; contudo, o crescimento do uso de materiais didáticos em cursos de ensino superior fez com que esse tema fosse trazido à pesquisa acadêmica.

A carência de estudos nesse âmbito apontou para a necessidade de, em um primeiro momento, identificar e compreender os elementos que constituem os layouts dos materiais didáticos produzidos para cursos de EAD realizados no Brasil. Esses elementos foram relacionados às teorizações de autores que abordam a temática de design e editoração para, com isso, compreender suas potencialidades. Tal ação representa o primeiro momento para a definição de quais seriam as melhores escolhas na constituição de um layout para materiais didáticos da EAD. Portanto, este escrito foca-se no levantamento e compreensão desse potencial.

\section{Metodologia: em busca de produções}

O momento de levantamento de elementos utilizados na constituição dos layouts que configuram os materiais produzidos para cursos de EAD e a compreensão de suas potencialidades configuram esta observação em um estudo de caso. Essa opção metodológica, segundo Araújo (2008), caracteriza-se pelo foco em uma situação ou aspecto em específico, para, posteriormente, ter-se uma compreensão global acerca do objeto ou fenômeno de interesse. Assim, como primeira etapa, foram contatadas instituições de ensino superior com cursos ofertados na modalidade EAD, a fim de buscar materiais produzidos e utilizados para esses cursos. A partir desse contato, foram utilizados materiais empregados em um curso de pós-graduação de alcance nacional, denominado "Arte, Educação e Tecnologias Contemporâneas (Arteduca)" - UnB; em um curso de graduação tecnológica denominado "Planejamento e Gestão para o Desenvolvimento Rural (Plageder)" - UFRGS, cujo público centralizou-se em um dos estados brasileiros; e, além destes, o material utilizado em um curso de Pedagogia cuja instituição está localizada no norte do Brasil. Após a recolha dos materiais, eles foram observados, elencando os elementos que constituem seus layouts. Em seguida, os 
aspectos destacados foram analisados, tendo em conta as teorizações advindas do campo do design que explicam sua necessidade e importância. Tais processos visam apontar aspectos de design que podem colaborar no processo de ensino e aprendizagem na EAD.

\section{Resultados e Discussão}

\subsection{Material 1 (Brennand \& Rossi, 2007)}

O primeiro material analisado foi desenvolvido para o curso de graduação em Pedagogia ofertado na Universidade Federal da Paraíba (UFPB), em 2009, e estruturado em oito publicações em volumes, cada uma correspondendo às disciplinas de um semestre (cada semestre teve entre seis e nove disciplinas). O material ao qual se teve acesso constituiu-se em arquivos digitais (PDF - Portable Document Format) e, segundo informações da coordenação do curso, teve uma versão impressa exatamente igual. Organizado em páginas de formato A4, ele apresenta as seguintes partes estruturantes: capa, ficha catalográfica - ISBN, ficha técnica, epígrafe, sumário, metodologias e apresentação, mapa conceitual, croqui de percurso, unidades, aulas, textos e desafios (Figura 1).
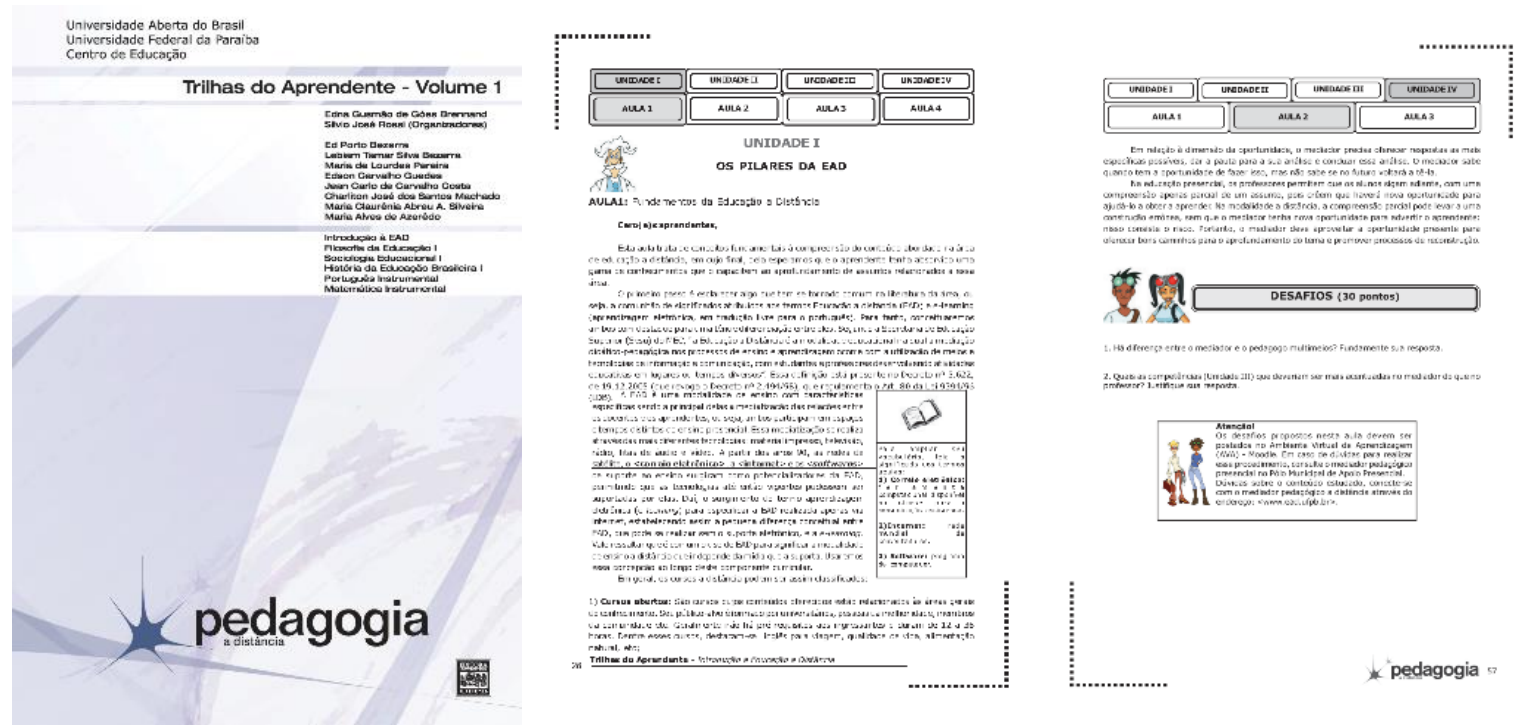

Figura 1: Material 1 (Brennand \& Rossi, 2007). 


\subsection{Material 2 (UnB, 2004)}

O segundo material de nossa pesquisa foi desenvolvido para o curso de pósgraduação latosensu "Arte, Educação e Tecnologias Contemporâneas (Arteduca)" oferecido na Universidade de Brasília (UnB), em 2004, e estruturado em 12 módulos. 0 material ao qual se teve acesso constituiu-se em 12 arquivos digitais (PDF), cujas páginas eram de formato $\mathrm{A} 4$, e apresentava as seguintes partes estruturantes: apresentação, desafios, textos, atividades e referências (Figura 2).

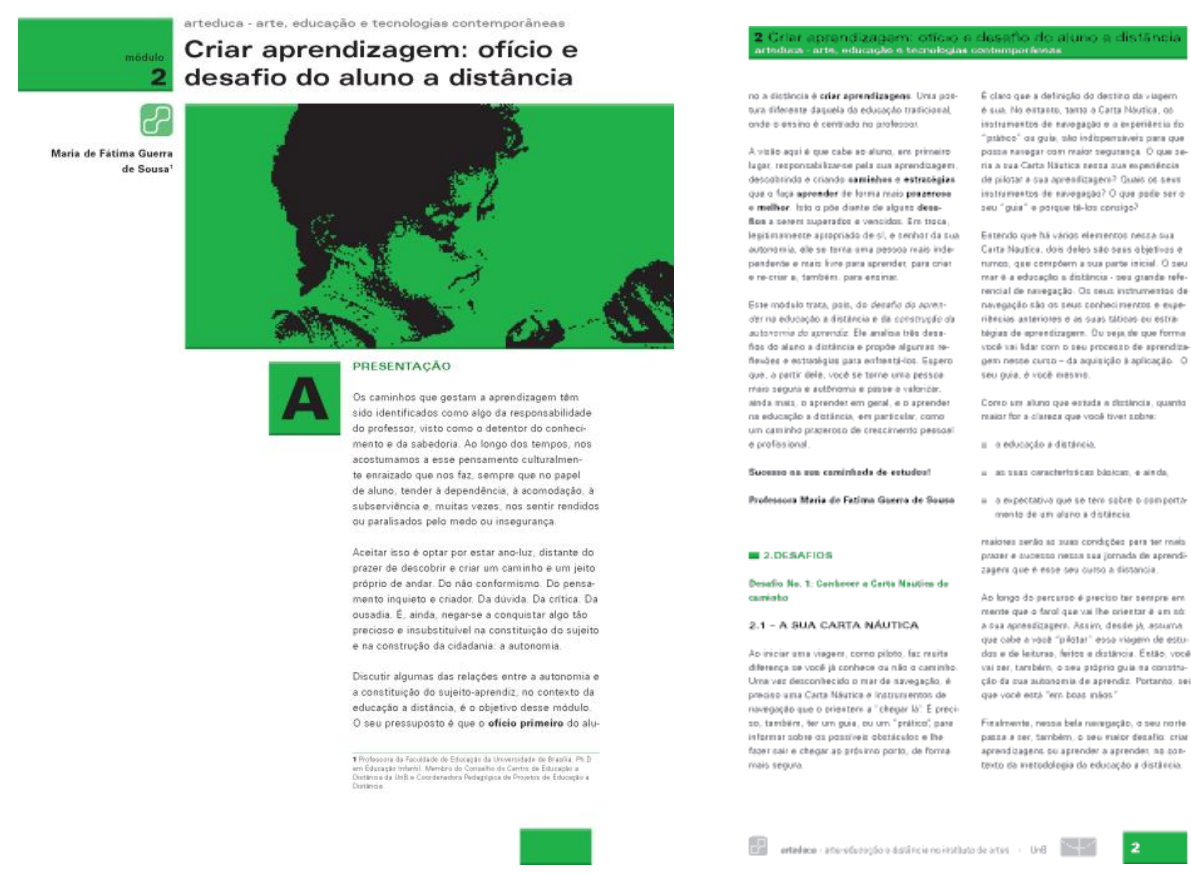

Figura 2: Material 2 (UnB, 2004).

\subsection{Material 3 (UnB, 2011)}

O terceiro material foi desenvolvido para o curso de pós-graduação latosensu "Arte, Educação e Tecnologias Contemporâneas (Arteduca)" oferecido na Universidade de Brasília (UnB), em 2011, e estruturado em 14 módulos, cada um disponibilizado em um arquivo digital (PDF). Suas páginas eram de formato variado (A4 e A5) e ele apresentava as seguintes partes estruturantes: capa, textos e referências (Figura 3). 


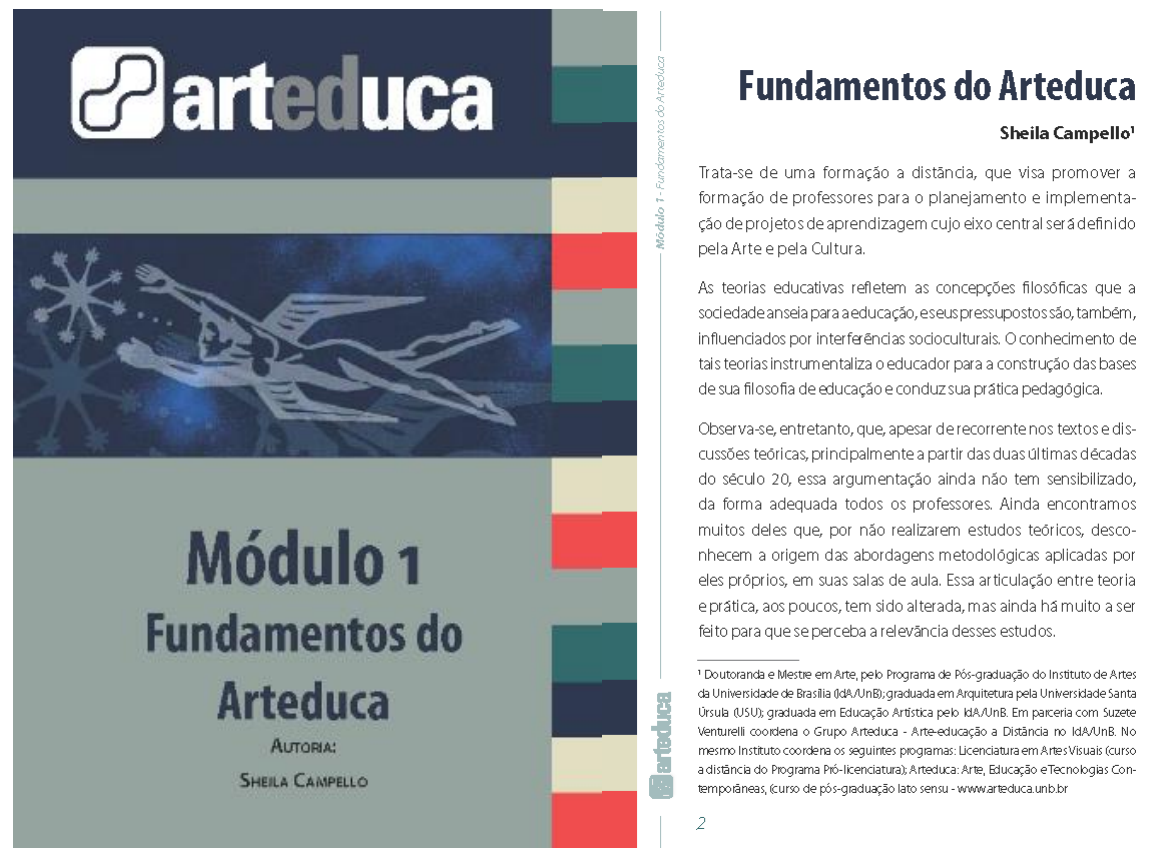

Figura 3: Material 3 (UnB, 2011).

\subsection{Material 4 (Sead/UFRGS, 2007)}

Finalmente, o quarto material que utilizamos em nossa pesquisa foi desenvolvido para o curso de graduação denominado "Tecnologia em Desenvolvimento Rural (Plageder)", ofertado na Universidade Federal do Rio Grande do Sul (UFRGS), no ano de 2007. Esse curso foi organizado em seis semestres, que eram compostos de quatro ou cinco disciplinas, somando 27 disciplinas, para as quais foi elaborado o material em publicações independentes. Havia um arquivo digital (PDF) para cada disciplina do curso, tendo sido disponibilizado aos alunos, também, o formato impresso, exatamente igual ao digital. O material, organizado em páginas de tamanho $17,5 \mathrm{~cm} \times 25 \mathrm{~cm}$, apresentava as seguintes partes estruturantes: capa, ficha catalográfica - ISBN, ficha técnica, sumário, lista de figuras, introdução, unidades (introdução, objetivos, texto, atividades, referências) e glossário (Figura 4 ). 


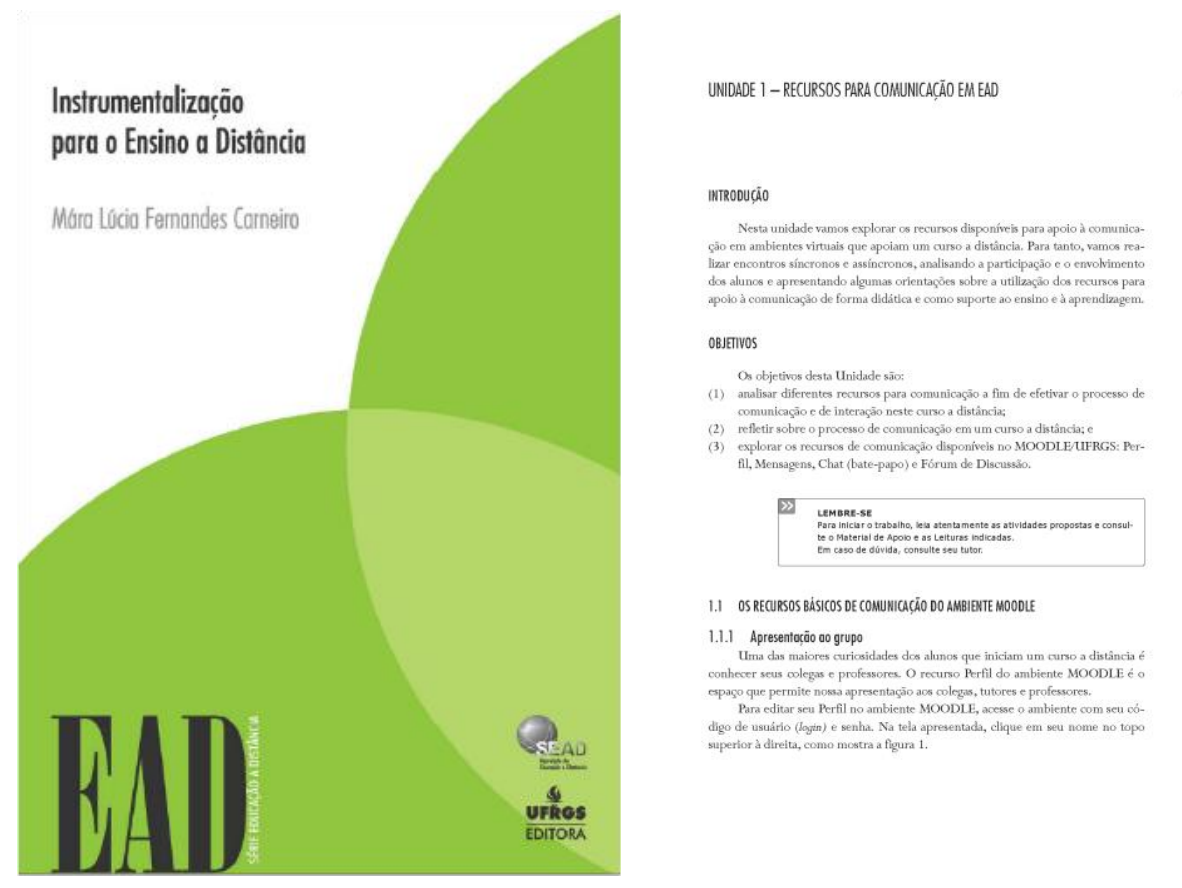

Figura 4: Material 4 (Sead/UFRGS, 2007).

\subsection{Comentários acerca dos materiais observados}

Os comentários descritos a seguir trazem observações de elementos do design e editoração apoiados em Lidwell, Holden e Butler (2010) e em White (2006). Vale dizer que os autores supracitados não abordam especificamente aspectos do design para publicações didáticas utilizadas na EAD, contudo, apresentam aspectos gerais e sinalizam a possibilidade de serem utilizados em diferentes âmbitos.

O primeiro aspecto observado é o modo como as publicações foram organizadas. Nos cursos de graduação, percebe-se que todo o material correspondente a uma disciplina está organizado em um único arquivo ou volume, sendo assim, supõe-se que foi disponibilizado aos alunos no início dos estudos. Esse modo de acesso ao material pode motivar os alunos a consultá-lo apenas em um momento, visto que há a curiosidade em conhecer o material no momento do recebimento, e, com o tempo, essa curiosidade pode ir se perdendo. No caso do material desenvolvido para o curso de pós-graduação, dividido em módulos, estes estão organizados em arquivos independentes, que não especificam por quanto tempo de estudo serão utilizados. Porém, sua distribuição pode ser gradual, módulo a módulo, trazendo sempre um elemento de curiosidade pelo que haverá para ser estudado em cada módulo. 
Nos materiais oriundos de cursos de graduação, que possuem versões impressas, observou-se o registro junto ao sistema International Standard Book Number (ISBN). O registro no ISBN é um elemento importante, pois é uma forma de garantir a autoria tema de muita discussão no contexto da EAD - e suprir as exigências de produções docentes.

Atenta-se, também, para o tamanho e a orientação da página(A4 na posição retrato), dimensão geralmente utilizada para produções impressas, tais como documentos, trabalhos de estudantes etc. White (2006) alerta que qualquer tipo de material produzido deve levar em conta o seu manuseio, aspecto distinto em cada tipo de produção. No caso de materiais disponibilizados em meios digitais, é preciso considerar que os elementos aparecem na tela sob o formato de uma página e sua posição plana permite que todos eles sejam vistos de modo frontal e de uma única vez, sem que seja necessário correr os olhos pela página. Os materiais observados apresentam um formato de página que necessita de barra de rolagem para ser lida em meios eletrônicos. Tal formato não favorece o material, o ideal seria uma página que pudesse ser vista completamente em uma tela de qualquer dispositivo eletrônico, sem o uso da barra de rolagem.

O formato digital em PDF é comum em todos os materiais observados, o que possibilita a abertura do arquivo sem que ocorram desconfigurações, independentemente do dispositivo utilizado. Essa opção, adotada pelos cursos, torna o material mais acessível, aspecto levantado como favorável por Lidwell, Holden e Butler (2010). Evidentemente, para além deste, há outros aspectos acerca da acessibilidade, tais como aqueles que dizem respeito às capacidades sensoriais e físicas. Contudo, é válido enfocar aqui a importância de disponibilizar um material em um formato em que ocorra o mínimo de desconfigurações, erros ou quaisquer dificuldades de operá-lo.

Nota-se a presença de uma organização dos materiais no que concerne a sumários e textos de apresentação/introdução nos materiais dos cursos de graduação. Tais elementos constituem um organizador prévio, citado como importante por Lidwell, Holden e Butler (2010), por apresentar informações e descritores que exibem um material novo, com o objetivo de facilitar o uso e a aprendizagem. Nos processos pedagógicos da EAD, tais elementos são imprescindíveis para que os alunos sejam inseridos e preparados para o processo de estudo. 
White (2006) atenta para a captura do leitor para o material, enfocando que, antes mesmo de chegar ao texto, ele pode ser motivado à leitura pelo uso de imagens e títulos sugestivos. Aspectos que constituem a mancha gráfica, como textos organizados em pequenos blocos, motivam mais o leitor. Essa constatação está diretamente ligada à primeira impressão que ele tem em seu primeiro contato com o material. É também nesse contato que se observam os modos como os elementos compositivos são arranjados e se relacionam entre si no espaço. Para White (2006), não importa o que estará disposto e em que espaço, mas sim o que chama atenção da página para os olhos do leitor, o que vai impressioná-lo, encantá-lo. Sobre essa questão, nota-se que os materiais apresentam uma organização visível ao primeiro olhar, bem como uma página em que os elementos não sobrecarregam o espaço, deixando um aspecto leve, o que se configura como um motivador para iniciar a leitura.

Um aspecto que também pode ser entendido como motivador para o estudo/leitura é a ação de combinar várias unidades de conteúdo em pequenas quantidades. Lidwell, Holden e Butler (2010) denominam-na de segmentação, e apontam que, desse modo, a informação torna-se mais fácil de processar e memorizar, logo, favorável ao processo de aprendizagem. Vale considerar que o aluno, ao se deparar com textos longos e densos, fica, frequentemente, desmotivado à leitura. Nos materiais observados, não se percebeu uma ação de segmentação muito clara, porém eles possuem uma organização que intercala textos e atividades, principalmente nos cursos de graduação. Nos materiais advindos da pós-graduação, por sua vez, notam-se textos mais longos e sem a presença de atividades.

White (2006) alerta para a sequência de páginas e o ritmo criado com o movimento do passar delas. O autor sinaliza que é preciso pensar nas páginas como um conjunto. Evidentemente, cada uma delas tem suas especificidades, porém, todas formam um conjunto e devem ser assim consideradas; por isso, precisam estar relacionadas como se fossem uma sequência de ações. Sob esse aspecto estão a repetição e a padronização, elementos que criam força e identidade. É pela repetição rítmica que se consegue uma coerência visual, uma estrutura de previsibilidade e a sensação de ordem e hierarquia. Por isso, é preciso pensar na forma e na ordem em que as informações chegam ao leitor, e as implicações disso em relação ao objetivo da produção. No caso observado, estão envolvidas informações que aparecem recorrentemente nos materiais, tais como o título do módulo/unidade e a identificação do curso, encontradas nos materiais 1, 2 e 3 . Destaca-se, no material 1 , a constante 
presença de um menu superior, indicando não apenas o título da unidade, mas o número correspondente a ela, fato que localiza o aluno.

Boa legibilidade, ou seja, clareza visual do texto baseada em tipografia, tamanho, contraste, bloco e espacejamento é um aspecto também abordado por ambos os autores, já supracitados. A escolha de tipos para compor o material pode se tornar algo infinitamente complexo em um tempo em que existem inúmeros tipos de fontes, além daquelas que estão sendo criadas a todo momento. A atual gama de fontes apontou para o fato de que elas trazem consigo significados e podem estar em complemento ao texto, assim como destoar dele. A fonte deve ser confortável para o leitor e precisa fazer sentido em relação às palavras. White (2006) alerta que o conforto vem daquilo que nos é conhecido: sair da zona de conforto nos coloca em uma situação confusa e insegura. No contexto dos tipos de fontes, está imbricado o destaque, que pode ser pelo uso de grifos (negritos, itálicos, sublinhados etc.) e/ou com formatos Caixa Alta e baixa. O uso em excesso desses itens pode trazer dificuldades na leitura do texto, por isso, merecem lugar apenas quando o efeito desejado é de destaque. Tanto Lidwell, Holden e Butler (2010) quanto White (2006) alertam que cabe destacar elementos que necessitam ser observados pelo leitor. Para isso, indicam ser propício fazer uso do contraste, algo que se destaque e sobressaia do restante do texto. Podem ser usados espaços em branco ou sobrecarregados, mudanças de posição, alinhamentos diferenciados, grifos, tamanhos, cores, tipos de fontes, imagens etc., enfim, há uma infinidade de maneiras de sobressaltar a informação para o leitor. Nota-se, nos materiais observados, a presença de realces, principalmente em títulos, por meio do uso de fonte em negrito ou Caixa Alta. Ao longo do texto, os materiais 2 e 3 apresentam alguns termos em realce, com o uso de cores distintas ao corpo do texto.

O grande número de opções de fontes pode motivar o uso de várias tipologias em uma única página, fator que coloca em evidência os tipos, e não o conteúdo; a fonte é um elemento que torna visíveis as informações que pretendem ser transmitidas, portanto, deve complementar o conteúdo, e não competir com ele. Uma boa escolha de fonte também passa pela textura gráfica, que resulta do texto como a mancha gráfica da página. Na mancha gráfica deve ser possível ver claramente cada um dos elementos, ou seja, cada uma das letras, de modo que tenham um ritmo. Na textura do texto deve ser possível identificar cada uma das letras e palavras, por isso, ela não deve ser uma única mancha em que não se identifiquem as pequenas partes. Os materiais observados 1,2 e 3 apresentam fontes agradáveis para serem lidas em meios tecnológicos, fontes 
não serifadas. Já o material 4 apresenta uma fonte serifada bastante comum em publicações impressas, não aconselhada para meios digitais.

Em todos os materiais, como já dito, é utilizada a opção Caixa Alta para títulos ao longo do texto e, em alguns momentos, há a utilização de negritos (bold). Títulos e subtítulos constituem o primeiro contato com o conteúdo da informação, é através deles que o leitor identifica o contexto da produção como um todo e se localiza nele. Por isso, essas chamadas textuais precisam ganhar destaque, podendo ser por meio de um grifo ou de um tamanho de fonte: para White, "os títulos expõem seu conteúdo pela sua forma" (2006, p.110). Devem ser curtos e ganhar destaque, de modo que proporcionem impacto na leitura. Ao designer cabe desenvolver um estilo que identifique os títulos na publicação, para que o leitor também seja capaz de identificá-los.

Ainda com relação aos textos, outro aspecto importante, trazido por Lidwell, Holden e Butler (2010), diz respeito ao alinhamento das margens e às bordas. Os autores destacam a importância de manter um único modo de alinhar os textos, de forma que eles conduzam o olhar, criando, assim, um referencial.

Também presente nas publicações são as imagens, que acabam por ser a primeira coisa a ser vista em uma página. São emocionais, despertam curiosidade e introduzem e/ou complementam a informação ao leitor, por isso possuem papel importante em materiais didáticos. Mas seu uso necessita deum objetivo claro para estarem presentes na página. Nota-se, nos materiais observados, baixa presença de imagens, sendo que apenas o material 1 faz uso de imagens representativas. Contudo, quadros e tabelas são constantes em todos os materiais. No material 1, aparecem, no que concerne a imagens, elementos icônicos pictóricos, que estão relacionados a determinadas partes estruturantes do material. Um exemplo é a imagem de um rolo de filme, para indicar que está sendo sugerida uma produção cinematográfica. Esse aspecto é destacado por Lidwell, Holden e Butler (2010) como um elemento para melhorar o reconhecimento e a memorização do conteúdo pelo aluno.

Boxes e fios também são utilizados e têm por função dar destaque ou organizar o espaço. Os boxes chamam a atenção do leitor para o que está inserido nele. Já com os fios, pode-se limitar o espaço de leitura e organizar os elementos na página, assim como usá-los como referencial para o alinhamento de outros elementos. Notou-se, no material 1, grande utilização de boxes com títulos, ou com partes textuais que mereciam destaque. 
White (2006) aponta a cor como um elemento que requer muita atenção por parte do designer, assim como os tipos e o espaço. A escolha das cores não deve estar relacionada ao gosto pessoal do editor, mas aos objetivos e significados que elas produzem no momento de leitura. Em alguns casos, elas estão presentes no fundo ou em boxes e fios, necessitando de atenção redobrada, visto que podem ser influenciadas pelas cores de fundo, fontes e de outras imagens, e, assim, não alcançar o objetivo desejado. Cores são um grande trunfo e termos de destaque e organização visual, e a elas são atribuídas implicações psicológicas e culturais. Diante disso, é preciso conhecer o efeito das cores sobre o público a quem se destina a publicação. Os materiais 2 e 3 apresentaram grande utilização da cor como elemento organizador dos módulos, usando uma cor como referência para cada um. Os outros materiais, 1 e 4, não apresentaram cores ao longo dos textos, sendo elaborados em fundo branco e fonte preta. No caso do material 1, utilizou-se apenas uma gradação de tons de preto (originando a cor cinza). A utilização de fundo branco e textos na cor preta, constante em todos os materiais observados, proporciona o contraste entre figura e fundo, ideal para uma boa leitura, conforme apontado por Lidwell, Holden e Butler (2010).

Vale lembrar White (2006), quando enfatiza que uma página é a síntese de vários elementos: tamanho da página; número de páginas; linguagem usada; técnica; fórmulas científicas; "quantidade" de tipologia a ser lida; cobertura; margens e espaços entre colunas; de que modo o texto é construído ou dividido; como a peça é impressa e segurada na mão; peso, cor, textura, brilho do papel; e qualidade e resolução da impressão. White apresenta a edição e o design de uma publicação, entendendo-a, sob os diferentes formatos, como uma produção que merece atenção em todos os detalhes, sempre associados ao seu propósito. O público e o objetivo da produção são fatores primordiais na escolha dos elementos de editoração gráfica e dos modos como estes serão apresentados ao final do desenvolvimento da produção. Ainda, o autor coloca que o uso de padrões utilizados em publicações impressas, formato já conhecido pelo público, em meio eletrônico pode ficar monótono. Porém, é válido considerar que, se utilizados, serão reconhecidos facilmente pelos leitores e, portanto, sua compreensão torna-se mais efetiva.

Por fim, é importante ressaltar a necessidade de desenvolvimento de um design transparente, no qual as informações- principalmente aquelas que orientam, como links, caixas que ressaltam textos, entre outras-necessitam ser consideradas óbvias para os usuários. Em outras palavras, não devem exigir que o usuário pense sobre sua função, 
fato que desviaria o foco do estudo e, por consequência da sobrecarga cognitiva, causaria dificuldades no processo de aprendizagem. Grando, Konrath e Tarouco (2003) atentam para o fato de que um design complexo ou não convencional eleva a carga cognitiva, pois exige do usuário, para além do conteúdo que busca, o entendimento do espaço; por outro lado, um layout com uso convencional dos elementos proporciona a sensação de familiaridade com o espaço, facilitando sua interpretação.

\section{Considerações Finais}

Teorizações sobre materiais didáticos têm despontado com mais frequência a partir do advento dos cursos da educação formal na modalidade a distância. No entanto, ainda são restritas e, muitas vezes, voltadas para questões de elaboração do conteúdo e logística de produção. Aspectos relacionados ao design visual ainda se mostram bastante iniciais, fato levantado por Moraes (2008) acerca dos livros didáticos. O autor afirma que a importância do livro didático vai para além do conteúdo que ele traz consigo, afinal sua estrutura tem influências "formação cultural, incluindo o gosto e a informação estética" (p. 141) dos indivíduos. Ainda assim, o design dessa categoria de publicação não é analisado ou explorado e parece que essa questão é semelhante nos materiais para EAD.

Neste artigo, buscou-se realizar um levantamento acerca do que tem sido produzido sobre o tema aqui abordado no contexto brasileiro. Em suma, pode-se dizer que as produções de materiais para EAD em meios eletrônicos pouco diferem, visualmente, de materiais impressos, mesmo que utilizados com outras tecnologias. Talvez, neste momento em que muitos alunos da EAD estão familiarizados com o livro didático impresso, isso possa ser um facilitador da familiarização com o objeto e o espaço de estudo; no entanto, à medida que o público da EAD for se caracterizando por aqueles estudantes familiarizados, desde a infância, com as multilinguagens, o material necessitará de outro layout.

De um modo geral, nota-se a preocupação em produzir materiais que não apresentam muitas cores em seu espaço visual. A forma como elas são utilizadas sugere serem um elemento que caracteriza o material, dando-Ihe singularidade. Desse modo, o objeto ganha uma identidade, que facilita o reconhecimento do usuário. Outro ponto forte a ser considerado é o modo de estruturação do texto, dividido em unidades e 
pequenos parágrafos e/ou subpartes, fato que torna a leitura mais leve, facilitando e motivando o usuário para o estudo.

Uma questão que merece ser retomada é o modo de distribuição do material: quando disponibilizado uma única vez, sob o formato de um volume a ser utilizado ao longo do período de estudo, há grande possibilidade de o aluno o deixar de lado. Já uma disponibilização semanal, tal como sugere o material observado nos cursos de pósgraduação, gera uma rotina que o aluno necessita seguir, e isso o auxilia na organização de seus estudos, facilitando os resultados de aprendizagem em EAD.

Considera-se que este texto apresenta um recorte pequeno e está em fase inicial, podendo surgir muitas possibilidades sobre o assunto, em diversas áreas do conhecimento. É preciso que outras investigações e novos objetos sejam observados, a fim de se obterem possibilidades efetivas no ensino e aprendizagem a distância, a partir de elementos do design. Isso auxiliará o trabalho do professor, que, muitas vezes, acumula para si essa função de designer, ao produzir seus materiais.

\section{Referências bibliográficas}

Araújo, C. (2008). Estudo de caso: métodos de investigação em educação. Estudo de caso. Universidade do Minho. Disponível em http://grupo4te.com.sapo.pt/estudo caso.pdf

Belisário, A. (2006). O material didático na educação a distância e a constituição de propostas interativas. In M. Silva. Educação online: teorias, práticas, legislação e formação corporativa (pp. 137-148). São Paulo: Loyola.

Brennand, E., \& Rossi, S. (2007). Trilhas do aprendente. Recife: Liceu.

Grando, A., Konrath, L. P., \& Tarouco, L. (2003). Alfabetização visual para a produção de objetos educacionais. Novas Tecnologias na Educação, 1(2). Disponível em http://rived.mec.gov.br/artigos/artigoanita.pdf

Illera, J. L. R. (2010). Os conteúdos em ambientes virtuais: organização, códigos e formatos de representação. In Coll, C. \& Monereo, C. (Orgs.). Psicologia da educação virtual: aprender e ensinar com as tecnologias da informação e da comunicação. (pp. 136-154). Trad. Naila de Freitas. Porto Alegre: Artmed. 
Lidwell, W., Holden, K., \& Butler, J. (2010). Princípios universais do design. Porto Alegre, Bookman.

Morais, D. (2008). A renovação visual do livro didático no Brasil. In Congresso brasileiro de pesquisa e desenvolvimento em design. São Paulo, AEND.

Moran, J. (2002). O que é educação a distância. Acesso em 10 de fevereiro de 2013, disponível em http://www2.eca.usp.br/moran/wpcontent/uploads/2013/12/dist.pdf

Peters, O. (2009). A educação a distância em transição. São Leopoldo: Editora Unisinos. Sead/UFRGS (2007). Curso de graduação tecnológica:Planejamento e Gestão para o Desenvolvimento Rural da Sead/UFRGS (Plageder). Série Educação a Distância. Porto Alegre: Editora da UFRGS.

White, J. V. (2006). Edição e design: para designers, diretores de arte e editores. São Paulo: JSN Editores.

UnB (2004). Arte, Educação e Tecnologias Contemporâneas (Arteduca). Brasília.

UnB (2011). Arte, Educação e Tecnologias Contemporâneas (Arteduca). Brasília.

Weber, D., \& Oliveira, L. R. (2014). Material didático: um espaço pedagógico na EAD. In XI Colóquio sobre Questões Curriculares/ VII Colóquio Luso-Brasileiro sobre Questões Curriculares/ I Colóquio Luso-Afro-Brasileiro sobre Questões Curriculares (pp.976 - 981). Braga.

Weber, D., \& Oliveira, L. R. (2013). Produções didáticas para a educação a distância: comunicação, instrução, organização. In II Seminário Diálogos em Educação a Distância (pp.327 - 336). Rio Grande. 